\section{NisRec Sciencepark Research, Organization \& Counseling \\ Global Journal of Arts Education}

Volume 07, Issue 1, (2017) 26-33

www.gjae.eu

\title{
The pre-professional development of teenagers' graphical skills within integration approach
}

Zilia Muchtarovna Yavgildina*, Kazan (Volga region) Federal University, 420021, Kazan, Russian Federation. Nadegda Valentinovna Mishina, Kazan (Volga region) Federal University, 420021, Kazan, Russian Federation. Anastasia Valentinovna Mishina, Kazan (Volga region) Federal University, 420021, Kazan, Russian Federation.

\section{Suggested Citation:}

Yavgildina, Z. M., Mishina, N.V. \& Mishina,A.V. (2017). The pre-professional development of teenagers' graphical skills within integration approach. Global Journal of Arts Education. 7(1), 26-33

Received September 17, 2016; revised November 18, 2016; accepted February 2, 2016.

Selection and peer review under responsibility of Prof. Dr. Ayse Cakir Ilhan, Ankara University, Turkey. (C)2017 SciencePark Research, Organization \& Counseling. All rights reserved.

\begin{abstract}
The pre-professional training of students in children's art schoolsrequires the development of a new methodology and content basis. This article examines the notion of the pre-professional development of graphical skills as a fundamental element of artistic training that includes Four components (cognition, knowledge, practice and motivation) and it is performed step-bystep. The application of an integrative approach is viewed as an effective means of the pre-professional development of teenagers' graphical skills. The study describes the principle of integration applied for the artistic acquisition of the world. This integration approach has formed the base for the author's original course, "Computer and Graphical Art" which was implemented at the experimental stage of this study. The diagnostics of the pre-professional development of graphical skills among teenagers in the experimental group demonstrated the effectiveness of the integrative approach. The research methods included observations, a survey, test, and expert evaluation. The article discusses details of teenagers' graphical skills development within the integrative approach and experimentally proves the effectiveness of author's original academic program.
\end{abstract}

Keywords: pre-professional training, graphical skills, integration principle, integrative approach.

*ADDRESS FOR CORRESPONDENCE: Zilia Muchtarovna Yavgildina, Kazan (Volga region) Federal University, 420021, Kazan, Russian Federation. E-mail address: zilia.javgi@gmail.com 
Yavgildina, Z. M., Mishina, N.V. \& Mishina,A.V. (2017). The pre-professional development of teenagers' graphical skills within integration approach. Global Journal of Arts Education. 7(1), 26-33

\section{Introduction}

Current social and economic innovations have introduced and reformed children's secondary education in art schools. Modern children's schools of art need to become centers of learners' preprofessional art training. It increases training demands. Learners need to develop spatial thinking and should be able to operate with graphical images, capture artistic ideas by graphical means; capture new, unavailable off-the-shelf reality (advertisement, sign, and logotype), visualize and transmit information in a laconic, conventional and graphical form. These requirements update the objectives of teenagers' graphical skills development.

The literature review of studies in the fields of psychology, education, and art speak for the significance of the study of pre-professional graphical training of teenagers.

Numerous research studies have examined the questions related to the effectiveness of graphical training. Botvinnikov and Lomov studied research-based grounds of graphical skills, knowledge and expertise among schoolchildren; Alekseev, Gerver, Savelieva, and others analyzed questions of learners' artistic development in graphical training; Chemodanova examined graphical training with the use of modern equipment and information technologies.

Recent studies have also updated methods of graphical training with the assistance of intellectual interactive graphical information technologies and automated project systems (see, for example Aleinikov, Vinogradov, Gorshkov, Erofeeva, Ovchinnikova and others). Works performed by Anisimova Vasilenko, Vahitov, Vinogradov, Golovenko, Zhukova, Klimenko, Lesher, Miheeva, Roitman, Khakimova, and others described and discussed characteristics of academic tasks performed in the process of graphical training.

Review of literature including dissertation theses speak for the existence of a sufficient number of fundamental studies which provide a solid theoretical foundation for the study of learners' graphical training.

Works by Russian and international scholars present teenagers' pre-professional graphical skills development as a system of four integrated components:

- Knowledge as set of holistic visual perception, spatial vision, and artistic thinking (Piazhe, 1994; Venger, 1969; Zaporozhets, 1964);

- Cognition that includes elementary professional graphic knowledge (Lomov, 1959);

- Practice that includes elementary professional graphical skills (Botvinnikov, 1979; Komarova, 1970);

- Motivation (goal) that combines professional motives, settings, and needs (Kuzin, 2004).

The following stages should be performed step-by-step for the effective development of teenagers' pre-professional graphical skills:

Stage 1: Motivation Building: When a student learns the significance of development of a particular graphical skill. This stage is essential for successful activity implementation and further professional artistic education. The stage is performed in the first and second years of study in art schools for children when learners acquire information about an art object about its essence, purpose, relevance, and usefulness. It builds the motivation to perceive the world via graphical means, acquire basic and elementary graphical skills, knowledge, and expertise.

Stage 2: Building Cognitive Basis: When the basic notions of methods, rules, laws of objects' graphical reflection are acquired. During classes children in art schools learn the notions of 'life drawing', 'perspective', 'vanishing point', 'skyline', 'sanguine', hard-soft graphical tools, etc. However, it is insufficient to understand the terms; learners should be able to apply graphical knowledge. Knowledge acquisition and its application need to be combined as the knowledge of graphical notions requires the reapplication.

Stage 3: Building of Reproduction and Perception Foundation: At this stage graphical knowledge is applied in model tasks while graphical skills, holistic visual perception, and spatial vision are formed. The stage is implemented in the third and fourth years of study. The third year prioritizes the formation of artistic thinking, spatial vision, sensitive and theoretic nature acquisition by means of holistic visual perception and sign modeling of objects, processes, actions, and subsequent tasks reproduction. In the fourth year of study in art schools children learn to solve graphical tasks by optimizing their actions and 
moving to the creative level. Thus this stage aims to introduce most common methods of graphical imaging used to convey information by graphical means, as well as to draw consciously images (sketching, drafting and other).

Stage 4: Building Production and Creative Foundation: This stage implies a unity of logical, visual, and spatial components of artistic thinking; mastering of previously acquired graphical skills, their creative implementation in non-standard artistic tasks with the assistance of innovative methods. The stage is implemented in the fifth and sixth years of study in art schools for children. It aims at developing learners' creative abilities when they apply previously acquired knowledge, skills, expertise, artistic thinking, holistic visual perception, and spatial vision while performing significant artistic graphical activity. As a result, students improve their ability to observe and analyze objects' size and form, develop their creative side and inclination for artistic rationalization of environment. Learners are involved in creative project activities that require the application of skills and abilities when carrying out individual or group project tasks.

Stage 5:Building Evaluative and Reflective Foundation: This implies the ability to reflect and selfreflect on the process and results of activities performed by means of certain graphical skills (Mishina, 2014).

The content of graphical skills is integral in nature. The integrity is viewed as one of the fundamental characteristics of graphical skills as it combines graphical activity skills (i.e. drafting, sketching, sketching from nature, imaginative sketching, and their implementation sequence); design graphical skills (an ability to visualize and transmit information in a laconic or conventional way with the help of expressive means); computer art graphical skills (an ability to capture graphical idea by means of computer technologies), etc. This fundamental characteristic of graphical skills' content and a need to develop psychological processes, knowledge, skills, and personal characteristics predetermined the selection of the integrative approach for developing teenagers' pre-professional graphical skills.

The term 'integration' means "the unification of parts or elements into a whole" (Lokshina, 1988). This research supports the idea that the integrative approach assists in expanding learners' academic abilities and cognitive interests.

The integrative approach implies gradual increase of interdisciplinary teenagers' activities creates the ground for integration of various types of art, namely, fine arts, decorative and applied arts, design, project graphics, architecture, and computer art. The approach suggests the integration of subjects in children's school of arts (hereafter CSA) with secondary school subjects. In particular, the study of historic events that effect change in art styles and trends, examination of national culture, the study of a compass, tabular drawing pens, a ruler, and computers involve the study of such school subjects as History, Technical Drawing, Geometry, Technology, Information Literacy, etc. Such interdisciplinarity requires CSA teachers' preliminary training in school subjects. These knowledge and skills help learners to carry out integrative art projects and determine interrelated topics in each discipline.

The integration principle used in various types of artistic acquisition of the world enables CSA teachers to present topics in more details, to address educational and developmental objectives, provide systematic acquisition of knowledge, expertise and skills, provide better awareness of actions and links between secondary and supplementary education.

The integrative approach and the integration principle applied to the artistic acquisition of the world provided foundation for author's original program for CSA 'The Computer and Graphical Art' aimed at improving teenagers' pre-professional graphical training.

\section{Methods}

This study employed an experimental design to test the effectiveness of the integration approach and the principle of integrating various types of artistic world acquisition. Particularly the level of preprofessional graphical skills development among teenagers was measured. The following criteria of preprofessional graphical skills development among teenagers were identified; personal motivation, cognition, and action and content.

The criterion of personal motivation evaluates the level of motivation, values, emotions, and senses of teenagers' personality, which are essential for integrative personal development and which in many ways; affect the success of pre-professional graphical training. 
The criterion of cognition evaluates the acquisition level of elementary professional graphical skills and notions; essential drawing laws (paper arrangement, proportions and scaling, structural design, perspective, dimension, etc.) and special terminology (vanishing point, skyline, sketch, draft, formoplast, etc.).

The criterion of action and content enables to measure how stable, deep and conscious are the following skills one can apply in non-standard, creative tasks and contexts; instrumental skills (control of drawing movements in terms of force, tempo, strokes, steadiness, unity, and flow of graphical tools; application of essential properties of graphical tools and techniques to convey texture and space); performative skills (application of light and shadow principles, linear perspective, proportions, structural design, spatial location of objects; sketching, brief sketching, idea-sketching); and expressive artistic graphical skills (application of artistic ideas and means to depict objects; line, stroke, spot, and their types; ability to express emotional and esthetic attitude towards reflected objects and events).

Based on the theoretical foundation that defines the skill as an efficient activity which is performed under new circumstances and which activates appropriate knowledge and expertise. On the diagnostic stage we identified three levels of teenagers' pre-professional graphical skills development.

High (optimal) level which implies proficient application of light and shadow principles and linear perspective; correct proportioning of the object and constructive drawing; coordinated and expressive spatial location of objects; ability to lay strokes that reflect the mood of a drawing and highlight the texture; variation and rational control of pressure force of drawing movements when graphic tools are in use; correct application of essential features and techniques of graphic tools to convey texture and space(pencil - hard, soft, hand pressure regulation intensity; ink, paint - flow, sharpness, ton, intensity when regulating hand pressure); ability to independently depict objects and highlight their individual features; appropriate application of drawing expressive means such as line, stroke, spot, and their types (i.e. intensity, weakness, plasticity); ability to express emotional and esthetic attitude towards reflected objects and events. A learner possessing high level of graphical skills application is able to apply these skills in new, non-standard situations independently, initiatively, creatively, and appropriately; the learner is aware of special terminology, possesses and applies the whole range of graphic knowledge and skills and use them in practice, as well as when acquiring new graphical knowledge independently.

Intermediate (sufficient) level implies that the learner possesses sufficient application level of light and shadow as well as linear perspective; makes insignificant mistakes in object proportioning and constructive drawing; performs spatial location of objects in a way that is not sufficiently expressive; learner's strokes correspond to the mood of drawing but highlight the texture only partially; the learner shows variation control of hand movements in terms of pressure force when applying graphic tools; demonstrates correct application of essential features and techniques of traditional and commonly used graphic tools to convey texture and space (pencil - hard, soft, intensity when regulating hand pressure); the learner is able to artistically depict an object when assisted by the instructor; shows appropriate application of some drawing expressive means; demonstrates unstable ability to reflect emotional attitude towards objects and events. The learner possessing the optimal level of graphical skills is unstable when transferring skills into new, non-standard situations, shows interest and initiative; possess good knowledge of special terminology, demonstrates a partial mastery in the range of graphic knowledge and skills.

Low (elementary) level implies that the learner shows incorrect and inappropriate application of linear perspective and principles of light and shadow; possesses intuitive object proportioning and constructive drawing; shows lack of expressiveness when depicting spatial location of objects; inability to reflect mood by strokes; demonstrates non-variation control of hand pressure when applying graphic tools; passive and inappropriate application of essential features and techniques of major and commonly used graphic tools to convey texture and space. The learner is unable to artistically depict objects; she/he demonstrates irrational and inappropriate application of drawing expressive means; unable to reflect emotional attitude towards objects and events. The learner possessing the critical level of graphical skills is slow, passive, and unable to transfer skills into new, non-standard situations, demonstrates lack of interest and initiative, has little knowledge of special terminology, possesses and applies superficial and most commonly used graphic knowledge and skills.

We have formed an experimental group (hereafter EG) and control group (hereafter CG) of 45 teenagers each, within the supplementary education institutions the Children's school of art №4 and the children's school of art named after Balakirev in Kazan. Learners had equal level of artistic background and academic progress. 
Based on the criteria of graphical skills development, namely, personal motivation, cognition, action and content; the study utilized the following data collection instruments; questionnaire designed by Jovayshi and modified by Rezapkina entitled "Opredelenie professional'nyh sklonnostey" ("How to determine professional disposition"; (the questionnaire elicit motives, interests to artistic and graphical activity and the need to acquire graphical skills); diagnostic testing (the test on image laws, graphical terms and notions); observation of teenagers' independent artistic activities; expert evaluation of learners' academic graphical and creative works.

The questionnaire involved surveying and revealed that, teenagers, on the one hand tend to grade their graphical skills as advanced, on the other hand, they underestimate graphical challenges and issues. It is important to note that teenagers fail to see the significance and the need to develop their graphical skills, knowledge, and expertise, and show little interest in graphics. We argue that this reveals that the teaching practices in art schools often involve methods of life drawings with performance work prevailingly over creative work; the teachers seem not to set the goal to train learners their professional self-determination.

The diagnostic testing involved a test "What do I know about drawing?" The test questions were grouped according to their complexity, i.e. multiple choice (one correct answer, 3 tasks), multiple choice (several correct answers, 2 tasks), constructing limited answer (6 tasks), constructing free answer (4 tasks), and matching (2 tasks). Such variety of question types enabled the researchers to test learners' reproductive knowledge as well as their judgment tracks, depth and stability of knowledge, and artistic application of knowledge.

The observation of teenagers' independent artistic involved the study of learners' behavior in tasksolving natural environment consistent with program requirements. We focused on how learners' do preliminary work (sketching, artistic search), whether they search for artistic tools to depict the image and do independent search for appropriate information to fulfill the task.

The method of expert evaluation of learners' graphical and creative works involved the study of developed diagnostic tasks based on the following parameters: 1) application of per formative graphical skills; 2) application of instrumental graphical skills; 3 ) application of artistic expressive graphical skills. The experts observed and evaluated teenagers' work according to stated parameters. Every parameter comprised from 1 to 3 points. Besides, 2 points were added if the learner answered experts' questions and specified any notion, law, or was able to describe ongoing or further actions (for example, stated the algorithm of depicting an object). By these questions experts estimated learners' awareness of special terminology, graphical terms, notions, laws, and thus estimated her or his knowledge of graphics. The experts were introduced into the content of their role beforehand. Thus, the guidelines which specify the parameters and notions were developed. The experts were three educators who do not work with teenagers. The experts' evaluations recorded in special cards were then translated into a score given according to the identified parameters.

\section{Results}

The methods were applied in the experiment conducted in the institutions of extra-curricular education, namely the Art School for Children №4 and the Art School for Children named after Balakirev in the city of Kazan, Russia. The experiment comprised three stages; confirmation, formation and control. At the confirmation stage the learners of the Art School for Children named after Balakirev constituted the experimental group (hereinafter EG) and learners of the Art School for Children №4 constituted the control group (hereinafter CG). Each group included 45 learners.

At the confirmation stage we examined the current level of EG and CG teenagers' graphical skills development and obtained the results (see Table 1).

Table 1. The level of EG and CG teenagers' graphical skills development at the confirmation stage of the experiment

\begin{tabular}{lll}
\hline Level & $\begin{array}{l}\text { The number of teenagers in } \\
\text { EG }\end{array}$ & The number of teenagers in CG \\
\hline Intermediate (sufficient) level & 15 & 17 \\
Low (elementary) level & 25 & 23 \\
\hline
\end{tabular}


The results presented in Table 1. demonstrates that most teenagers of EG and CG have no interest in graphical activities, performance and expressiveness in academic and creative works, poor cognitive abilities, superficial graphical knowledge and inadequate use of graphical tools. Thus, the majority of teenagers have low (elementary) level of graphical skills development and they are not able to perform more complex tasks of pre-professional level programs.

Thus, the formation stage of the experimental was carried out in order to increase the level of EG teenagers' pre-professional graphical skills by means of the systemic application of the integrative approach and the integration principle of various types of artistic world acquisition stated in the author's program Computer and Graphic Art. In the Art School for Children №4, the CG teenagers followed the program introduced by the Ministry of Education and Science of the Republic of Tatarstan "The integrated course on drawing, painting and composition for children's' schools of art" developed by Gilmutdinova and Khamidullin (Gilmutdinova, 2011).

The EG learners' pre-professional training rested on three parts:

- Motivation (short activation of previous knowledge about essential graphical drawing tools, skills and expertise).

- Systemic part (the application of systemic tasks and activities of gradual acquisition of graphic notions and construction of essential psychological processes).

- Development (the author's program Computer and Graphic Art was introduced to implement the integrative approach).

Based on the integrative approach, The Computer and Graphical Art course includes various ways of world acquisition and integrates knowledge and skills of different subjects.

1. The project graphics covers the topics of 'dry' and 'fluid' techniques of project graphics', 'the material, surface, texture, and structure and their expressive means in graphics' and other topics that enable natural materials imitation by art and graphics materials and tools that teenagers applied when constructing their designs for an architectural landscape.

2. The introduction to design. Within this subject the learners study the specifics of interior design and acquire the basics of forming, paper plastic art, and modeling. The EG teenagers constructed thematic interior models and sketches of children café interior, which was later implemented.

3. The folk art is a subject that studies a still-life in works by the Tatar artists, historical events in Tatar crafts and other topics that reveal painting techniques of the Tatar artists and involves the creation of a painting or graphics in a style under study.

4. The school subjects projects 'Save the animals' (a calendar), 'Friendship that unites cities and countries' (a souvenir notebook) that involve Biology, Geography, Technology, History, etc.

At the control stage of experiment, which followed the stage of formation, a post-test of EG and CG teenagers' pre-professional graphical skills development was administered, which enabled the researchers to measure progress level and the quality of study performed at the formation stage and the effectiveness of the course based on the integrative approach. The diagnostics results are presented in Table 2 below.

Table 2. The level of EG and CG teenagers' graphical skills development at the control stage of the experiment

\begin{tabular}{lll}
\hline Level & The number of teenagers in EG & The number of teenagers in CG \\
\hline Intermediate (sufficient) level & 18 & 23 \\
Low (elementary) level & 2 & 17 \\
\hline
\end{tabular}

The results presented in Table 2. are different from those in Table 1. Unlike the CG, the level of EG teenagers' graphical skills development has increased. The analysis of most EG learners' creative works show high and intermediate level of graphical skills, characterized by professional interest in graphic activities, complex development of all cognitive abilities, profound and deep graphical knowledge, creative and technical accuracy of works, and thoughtful application of graphical tools. Moreover, the majority of teenagers demonstrated well-organized preliminary sketching work, creatively searched for new ideas by graphical means, created expressive composition and unique art images actively used previously acquired knowledge, skills and expertise when performing creative tasks in non-standard graphical contexts. 
The results imply that the experimental work affected parts of teenagers' pre-professional graphical skills training. The EG learners demonstrated their readiness to reflect graphical ideas by modern computer technologies; they became more independent in searching, applying and combining of graphical tools and techniques in accordance with the idea, plot, and graphical (project) task. The experiment improved the ability to depict emotional and esthetic attitude towards objects and events; ability to visualize and transmit information by graphical expressive means in a laconic or symbolic way (to construct and operate graphical symbolic models, etc.).

The results of CG teenagers' works also showed the increased level of pre-professional graphical skills, however, the content and quality of graphical skills, knowledge and expertise revealed minor changes. Besides, CG learners, unlike EG students, performed the project task passively, with little interest and expressed concerns. Therefore many CG teenagers (17 learners) showed low (elementary) level of pre-professional graphical skills. Such results imply that traditional training program did motivate CG learners for improvement of their graphical literacy, did not provide conscious activities, did not induce learners for independent search for graphical tools and techniques and thus CG learners' graphical works were primarily performed by analogy with previously acquired algorithms. Besides, as CG group's class activities were not project-based, results showed no increase in learners' ability to selfreflect, show individuality, and do adequate self-evaluation of graphical skills development. At the same time, traditional academic program showed increased level of learners' graphical skills, and teenagers' involvement in familiar work; learners demonstrated good results, but only five teenagers achieved the high level of pre-professional graphical skills development.

\section{Conclusion}

A number of conditions raise an issue of pre-professional development of graphical skills among learners of art schools for children. First of all, artists' and designers' professional environment is being updated. The new context requires demonstrating well-developed spatial vision, readiness to manipulate graphical images, implement artistic and constructive ideas manually or automatically, to visualize and transmit data in laconic or symbolic graphical forms. Besides, extra-curricular education system, which includes art schools for children, is being modernized; specifically the federal state requirements are introduced and pre-professional training of learners becomes legislated.

Such changes speak for the need to develop theoretical and methodological basis for the question under study. The integrative approach and the principle of integration of various types of artistic world acquisition should be considered as the fundamental and effective approach.

To sum up, the process of teenagers' pre-professional graphical skills development is implemented most effectively in the following conditions are in effect: first, the process is seen as having four interrelated components: knowledge, cognition, practice, and motivation; second, it is based on sequential implementation of five stages, and third, it applies the integrative approach and the principle of integration of various types of artistic world acquisition, which was supported by the results of this experimental research study.

\section{Acknowledgements}

The work is performed according to the Russian Government Program of Competitive Growth of Kazan Federal University.

\section{References}

Botvinnikov, A.D. (1979). Academic basis of graphical knowledge, skills and expertise formation in pupils. Moscow: Pedagogika.

Gilmutdinova, O.A. (2011). The integrated course on drawing, painting and composition for children's' schools of art (2nd ed.). Kazan: The Kazan Art school publishing.

Komarova, T.S. (1970). The formation of graphical skills in pre-school children. Moscow: Prosveshchenie.

Kuzin, V.S. (2004). Drawing and sketching. Moscow: Academy.

Lokshina, S.M. (1988). A concise dictionary of foreign words. (10th ed.). Moscow: Russian language.

Lomov, B.F. (1959). The formation of graphical skills and knowledge in learner. Moscow: APN RSFSR. 
Mishina, N.V. (2014). The methods of teenagers' graphical skills development in course of art and project activity. The modern Modern issues Issues of science Science and educationEducation, 4. Retrieved from; http://www.science-education.ru/118-14397

Mishina, N.V., \& Yavgildina, Z.M. (2015). Pedagogical Potential potential of the Artisticartistic-Design design Activity activity within the Context context of Development development of the Graphic graphic Skills skills in Adolescents adolescents. The Social Sciences, 10, 633-638. Retrieved from; http://www.docsdrive.compdfs/medwelljournals/sscience/2015/633-638.pdf

Piazhe, Z. (1994). The selected psychological works. Moscow: The international pedagogic academy.

Venger, L.A. (1969). The education and upbringing (at preschool age). Moscow: Prosveshchenie.

Zaporozhets, A.V. (1964). The perception and action. Moscow: Prosveshchenie. 